\title{
BIOFUELS - TOWARDS OBJECTIVES OF 2030 AND BEYOND
}

\author{
Rafat M. Łukasik \\ National Laboratory of Energy and Geology, Bioenergy and Biorefineries Unit \\ Estrada do Paço do Lumiar 22, 1649-038 Lisbon, Portugal, rafal.lukasik@Ineg.pt \\ https://orcid.org/0000-0002-7805-5744
}

Article history: Received 23 April 2021, Received in revised form 4 May 2021, Accepted 5 May 2021, Available online 6 May 2021.

\begin{abstract}
The European (and global) energy sector is in a process of profound transformation, making it essential for changes to take place that influence energy producers, operators, and regulators, as well as consumers themselves, as they are the ones who interact in the energy market. The RED II Directive changes the paradigm of the use of biomass in the heat and electricity sectors, by introducing sustainability criteria with mandatory minimum greenhouse gas (GHG) emission reductions and by establishing energy efficiency criteria. For the transport sector, the extension of the introduction of renewables to all forms of transport (aviation, maritime, rail and road short and long distance), between 2021-2030, the strengthening of energy efficiency and the strong need to reduce GHG emissions, are central to achieving the national targets for renewables in transport, representing the main structural changes in the European decarbonisation policy in that sector. It is necessary to add that biomass is potentially the only source of renewable energy that makes it possible to obtain negative GHG emission values, considering the entire life cycle including $\mathrm{CO}_{2}$ capture and storage. Hence, this work aims to analyse the relevance of biomass for $\mathrm{CHP}$ and in particular, the use of biomass for biofuels that contribute to achieving carbon neutrality in 2050. The following thematic sub-areas are addressed in this work: i) the new environmental criteria for the use of biomass for electricity in the EU in light of now renewable energy directive; ii) current and emerging biofuel production technologies and their respective decarbonization potential; iii) the relevance or not of the development of new infrastructures for distribution renewable fuels, alternatives to the existing ones (biomethane, hydrogen, ethanol); iv) the identification of the necessary measures for biomass in the period 2020-2030.
\end{abstract}

\section{Keywords}

biofuel, biomass, renewable energy directive, hydrogen, ethanol

\section{The electricity and heat sectors from biomass}

During the decade 2021-2030, solid biofuels for electricity and or heat and cooling, under the terms of new renewable energy directive (RED II) [1], must also meet sustainability criteria. They must achieve minimum GHG reductions of $70 \%$ (for installations that start operating after $1^{\text {st }}$ of January 2021 ) and $80 \%$ (for installations that start operating after $1^{\text {st }}$ of January 2026). To be eligible for national targets for the introduction of renewable energies, new installations with a rated thermal power greater than $50 \mathrm{MW}$ of biomass must have systems for the combined production of electricity and heat and/or cooling (cogeneration or trigeneration). Although some exceptions are foreseen in the RED II Directive such as: i) small-scale installations, i.e., dedicated installations for the production of electricity with a nominal thermal power of less than $50 \mathrm{MW}$ of biomass; ii) medium-scale installations, between 50-100 MW, as long as the production takes place through the application of highly efficient cogeneration technologies, or for dedicated installations for electricity with the energy efficiency levels associated with best techniques available; iii) large-scale dedicated installations, with a rated thermal power above $100 \mathrm{MW}$ of biomass, as long as high efficiency cogeneration reaching a minimum net electrical efficiency of $36 \%$ is ensured; or iv) that electricity is produced by capturing and storing $\mathrm{CO}_{2}$ from biomass.

Considering the effect that the rules of RED II will have on the market for solid biomass for electricity and heat in the Europe, it can be concluded that biomass for the purpose of producing dedicated electricity does not make sense to be promoted, because these dedicated electricity plants will never reach the minimum GHG reduction values

https://doi.org/10.32933/Actalnnovations.39.4• ISSN 2300-5599 • C 2021 RIC Pro-Akademia - CC BY 
needed in a sector that urgently needs to be decarbonised. The alternatives to power plants dedicated to biomass could be achieved through small-scale thermal power plants (e.g., in low-density urban aggregates, but with the capacity for viable district heating solutions; with industries that consume heat), or use of biomass gasification technology for the production of biomethane, with $\mathrm{CO}_{2}$ capture, or finally, use of pyrolysis or hydrothermal liquefaction technology for the production of bio-oils, which through deoxygenation reactions with hydrogen produced by biomass gasification or water electrolysis, will allow the production of advanced fuels with GHG emission reductions close to $100 \%$.

\section{More sustainable alternatives for the use of biomass for bioenergy}

The potential approach for more sustainable use of biomass for bioenergy is the replacement of industrial boilers, working on natural gas or fuel oil. This means that a vast amount of fossil energy can be substituted by the renewable energy in the industry sector. In addition, the use of biomass to produce industrial steam easily reaches $90 \%$ energy efficiency and has economically affordable investments in an open market.

Another alternative for the use of biomass for bioenergy relies on the national commitments in the decarbonisation of the natural gas network. Hence, the promotion to produce biomethane, either from organic waste or from waste of lignocellulosic origin is especially relevant. However, whenever economically feasible, these systems must be coupled with $\mathrm{CO}_{2}$ capture that will make biomethane production positive from the point of view of carbon neutrality (or even with negative $\mathrm{CO}_{2}$ emissions). This technological solution must include the full recovery of residues from this technology, such as biochar, which can be used as a fertilizer or pH corrector for agricultural soils [2].

Other relevant aspect in the more sustainable use of biomass for bioenergy is a decarbonisation of the aviation fuel sector. It is especially relevant as the HEFA-SPK technology that converts bio-oils into aviation biofuels is currently a technology already certified by ASTM. The challenge is the sustainable production of bio-oils, hitherto only obtained unsustainably from oils of vegetable origin (soybean oil, palm oil, etc.) or in insufficient quantities from used cooking oils. Therefore, residual (renewable) biomass encompassing the following bioresources: forest, agricultural, organic, agro-industrial and algae (microalgae and macroalgae), is the best sustainable alternative to produce bio-oils for advanced biofuels.

Finally, it is important to bear in mind that the entry into the market of these new technological alternatives for the use of biomass, will imply expected increases in the price of residual biomass, but also will lead to additional gains in efficiency and productivity in the collection, logistics and supply operations of consumers and the importance of issues associated with the flow of biomass (imports/exports). This in turn will make possible to accelerate the creation of a new forest management model associated to the network of small and decentralised plants creating value locally and maintaining revenue in the region/community ensuring better penetration of the market.

\section{The transport sector and GHG emissions}

In the pre-covid era, the transport sector in the EU was responsible for almost $1 / 4$ of total greenhouse gas (GHG) emissions and still was depended on around 95\% (content energy) on fossil resources [3]. Electric mobility is the European bet, however significant effects are only projected in the medium term (post-2030) in terms of expressive contribution for carbon neutrality in the transport sector. Therefore, electric mobility should be complemented with other short-medium term solutions for rapid reduction of $\mathrm{CO}_{2}$ emissions that are currently more cost-efficient and are capable of being applied to all modes of transport (road - light and heavy; maritime - pleasure boats, medium large; rail and aviation), in the 2030 horizon. In this context, the use of advanced biofuels and other renewable fuels, are the viable and large-scale alternative until 2030. In addition to the carbon neutrality of most of these biofuels, there is an immediate improvement in national energy security and the potential for rapid replacement of current fossil fuels in the road sector, using the current fuel distribution infrastructures, accelerating the energy transition, and decarbonising this sector quicker. For this purpose, it is essential to achieve the rapid penetration of the market by different advanced technologies, of a thermochemical or biochemical nature, to ensure the production of gaseous biofuels, e.g., biomethane (synthetic natural gas, GNS), as well as for advanced liquid biofuels to replace diesel and gasoline. Another important aspect in terms of sustainable mobility are other energy vectors, such as hydrogen, produced by gasification of biomass or by electrolysis of water, however always with use of renewable energy of a variable nature. 


\section{Role of advanced biofuels by integrating a decarbonisation policy for the transport sector}

With the entry into force of the Paris Agreement on $4^{\text {th }}$ November 2016 [4], the EU and the World are seeking to provide a global and effective response to the urgent need to halt the rise in global average temperature and resolve, with determination, the challenges linked to climate change. In fact, carbon neutrality (reducing GHG emissions so that the balance between emissions and removals from the atmosphere is zero) was defined as one of the priorities of the European governments, having assumed this commitment at the United Nations Conference on Climate Change in Marrakesh in 2016 [5]. To operationalise this, the Alliance for the Decarbonisation of Transport was created, whose objective is to produce a map of integrated solutions that, in the mobility sector, help achieving the goal of GHG emission reduction and stop global warming [6].

Gaseous fuels - Hydrogen, biomethane and biogas, including electrofuels

Gaseous fuels (e.g. hydrogen and biomethane) have a high potential for improving European energy security, contributing both to reduction of imports of oil, coal and natural gas and to achieve carbon neutrality, according to the national action plans towards 2030 and beyond [7]. Gaseous fuels renewable production can be carried out by different integrated technologies.

Renewable fuels of non-biological origin (RFNBO or electrofuels) - The technologies known as Power-to-Gas (PtG) and Power-to-Liquid (PtL) use water, instead of biomass, as a renewable source. The production of $\mathrm{H}_{2}$ is carried out from the electrolysis of water, which requires high amounts of energy. Thus, the best way to achieve an adequate cost-efficiency is to use the surplus renewable energy production of a variable nature (e.g. eolic, hydro or photovoltaic) in certain periods of the day and/or night. There are three main technologies for water electrolysis: i) alkaline electrolysis; ii) electrolysis PEM (proton exchange membrane) and, iii) electrolysis of solid oxide. Alkaline electrolysis is currently the most cost-efficient technology; however, it is predictable that before 2030, PEM electrolysis can improve this cost-efficiency in PtG processes. Solid oxide electrolysis may also be an option in the future, especially if heat sources are available. The $\mathrm{H}_{2}$ produced by electrolysis when reacting with an external carbon source $\left(\mathrm{CO}_{\text {or }} \mathrm{CO}_{2}\right)$ and by methanation reaction produces methane. The resulting methane, or synthetic natural gas, can be injected into the gas distribution network or stored. An alternative would be the direct injection of $\mathrm{H}_{2}$ into the gas network. However, the amount of $\mathrm{H}_{2}$ that can be injected into a natural gas transport network is limited by specific rules and regulations in each country. This renewable methane production process has no direct $\mathrm{CO}_{2}$ emissions, and the use of an external carbon source contributes to the reduction of $\mathrm{CO}_{2}$ emitted by other processes. The main disadvantages of this process are still relatively low efficiency and high costs.

These RFNBO are not eligible for double counting under RED II but are eligible for the multiplier factor of 1.2 on their energy content, if used in air and sea transport, as long as they reach a value of minimum reduction of GHG emissions of $70 \%$ for installation operation by $1^{\text {st }}$ of January 2021 . However, only maritime transport should benefit from this incentive from RED II mostly due to the recent restrictions on the use of fuels containing high levels of sulphur. To make it happened, it is essential to invest in port infrastructures of compressed/liquefied natural gas, as only this way PtG or PtL technologies have a margin of progression.

Biomass-to-Hydrogen - One of the promising technologies for producing renewable hydrogen, in a clean and efficient way, is through biomass gasification. However, this technology is not currently competitive for commercial hydrogen production due to the lower cost of $\mathrm{H}_{2}$ obtained by natural gas steam reforming, a technology used to obtain more than $95 \%$ of current hydrogen. The introduction of a carbon emissions tax that penalises fossil-based processes, to the detriment of clean processes from renewable sources, will allow the diversification of technologies such as the production of hydrogen by electrolysis of water and hydrogen by gasification of biomass. The production of hydrogen by electrolysis of water has received a lot of attention from policymakers, mainly due to its role in the coupling the electricity and the gas sectors.

On the other hand, technology to produce $\mathrm{H}_{2}$ via electrolysis is energy intensive and is only feasible using electricity from renewable sources at very low cost. The production of hydrogen by gasification of biomass is more insensitive to the price of renewable energy, mainly because water electrolysis requires demineralized water at the entrance of the electrolyser, which is a bigger obstacle to its cost-efficiency in the short term than energy cost itself. In addition, the foreseeable scarcity of water in the future suggests that in the medium-term, the production of $\mathrm{H}_{2}$ 
from biomass becomes more economically and technologically effective. Although gasification, after application of commercial separation processes, allows obtaining a degree of hydrogen purity above $99.999 \%$ for its direct use in low temperature fuel cells either for stationary energy production systems or for use in electric mobility by fuel cell, in the short-term, renewable hydrogen should be seen more as an energy vector than as biofuel. In fact, its potential to contribute to the decarbonisation of the natural gas network is an alternative and helps to diversifies the end-use of hydrogen in both the industrial and residential sectors.

Biomass-to-Biomethane - The alternative to $\mathrm{H}_{2}$ produced by biomass gasification, this technology consists of converting biomass into biomethane either by gasification or by anaerobic digestion of organic waste.

In the first case, biomass-to-gas (BtG) technology consists of biomass gasification in a gas mixture (syngas) that can be enriched in biomethane. Additionally, BtG technology can be integrated with PtG technology, which allows to overcome the problem of hydrogen storage, since with the integration of these technologies, hydrogen can be efficiently converted into biomethane (with $\mathrm{CO}_{2}$ sequestration) and then easily stored in the natural gas network. Furthermore, the integration of the two processes can be very advantageous since the oxygen produced in electrolysis can be coupled to the gasification process, while the produced hydrogen can be used for biogas methanation or for the fuel cell. However, it is always necessary that the $\mathrm{CO}_{2}$ contained in the syngas, has to be separated before the reaction with $\mathrm{H}_{2}$.

In the second case, technology involving anaerobic digestion of residual biomass from agricultural and other organic matters, including municipal solid wastes, produces biogas in the well-known digesters coupled with the purification commercial systems, such as the Pressure Swing Adsorption (PSA). To avoid the release of $\mathrm{CO}_{2}$ into the atmosphere, the last can be captured by catalytic or biological methanation. Likewise, prior to the methanation process, it is necessary to subject the biogas to commercial cleaning processes to remove $\mathrm{H}_{2} \mathrm{~S}$. It should be noted that $\mathrm{CO}_{2} \mathrm{capture}$ increases the global sustainability of biomethane production technology. Another advantage of this technology is that the final $\mathrm{CO}_{2}$ stream obtained is sufficiently concentrated to allow the use of more economically viable sequestration technologies, therefore it is more efficient than the use of $\mathrm{CO}_{2}$ through its capture from the atmosphere. Although there are already demonstration units for these biomethane production technologies (bioLNG or bio-GNC), their cost-efficiency has not yet reached a commercially interesting value, especially in the absence of other positive externalities, e.g., $\mathrm{CO}_{2}$ tax emitted. In England, in Swindon, the company GoGreenGas (meanwhile acquired by Advanced Biofuels Solutions) [8] invested $30 \mathrm{M} €$ and received a European support of $13 \mathrm{M} €$ in a CDR gasification unit with a nominal conversion capacity of 1500 tonnes/year CDR in $4 \mathrm{MW}$ of biomethane expected to start operating in 2020. In the Netherlands, in Alkamaar, the company AMBIGO using ECN's proprietary gasification technology, using biomass, plans to enter the market soon, producing biomethane for injection into the natural gas network [9].

On the other hand, the use of biomethane in the road or maritime sector has been continuously postponed due to a lack of legislation and incentives. Per se, biomethane may have a quota that could vary between residual or significant depending on the country's energy policy. Considering the existing infrastructure in Europe, biomethane will have more advantages in long-distance road transport. Another effective alternative is the use of liquefied biomethane as a solution for the decarbonisation of maritime transport, as long as it follows the same path as LNG, which will undoubtedly be the future of marine fuels for many years. In fact, LNG of fossil origin in the short/medium term seems to be the most suitable route in maritime transport due to the entry into force, on $1^{\text {st }}$ of January 2020, of the legislation of the International Maritime Organization (IMO). This new legislation reduced the maximum sulphur content permissible in marine fuels from $3.5 \%$ to $0.5 \%$ forcing maritime transport to find an urgent alternative to Marine Fuel Oil (MFO), which has sulphur levels incompatible with the new IMO [10]. This urgent need for this new regulation was especially evident in case of last Suez crisis, which due to unprecedent blockage of the canal, the emission of sulphur pollution spiked [11]. Therefore, clearly, in the immediate future, the energy transition in maritime transport may involve mixing biofuels (without sulphur), e.g., biodiesel (up to 7\%), to the MFO and in the medium-term the most realistic scenario is the adaptation of ships to the use $100 \%$ LNG, which has the advantage that it can always be progressively replaced by bio-LNG (i.e. biomethane). Both LNG and bio-LNG comply with IMO legislation specifications, regarding the sulphur content and the emission of harmful particles that are formed when the ships burn fuel. Besides those new technologies have also been announced. The major cruise lines, such as the Italian Costa Cruiser, recently launched the cruise ship Costa Smeralda, entirely powered by LNG, and intends to increase its fleet of cruise ships powered by $100 \%$ LNG [12]. Other companies such

https://doi.org/10.32933/Actalnnovations.39.4•ISSN 2300-5599 • ( 2021 RIC Pro-Akademia - CC BY 
as MSC Cruises, Aida, and the American Princess Cruises, have announced "cleaner" ship alternatives. Other companies, such as the French Pronat, announced the hybrid engine that uses diesel and LNG. Norwegian cruise company Hurtigruten has started operating two hybrid ships, powered by diesel and batteries [13].

It should also be noted that there are other variant technologies of the BtG technology, namely the biomass-toliquid (BtL) technology (gasification followed by the Fischer-Tropsch reaction), where the final product is methanol instead of methane. In this case, only the first European commercial units in the Netherlands (Joint Venture of Air Liquide, Nouryon, Enerkem, Port of Rotterdam and Shell, location: Port of Rotterdam) [14], in Spain (Enerkem and Suez Ecoplanta Molecular Recycling Solutions; location: El Morell) [15] and Sweden (VaermlandsMetanol AB, location: Hagfors) all to produce methanol as a liquid fuel [16].

\section{Liquid fuels}

In the transport sector, biomass currently assumes a clear leadership role in renewable energies compared to existing technological solutions or those in a demonstration phase, especially in the context of the increasing production of advanced liquid biofuels, in line with the RED II [1]. The current indirect land use change (ILUC) Directive 2015/1513 [17] discouraged the use of endogenous raw materials "rich in starch" or saccharine that compete with the food market for the production of biofuels. It is done by imposing a maximum ceiling of $7 \%$ on all so-called first-generation biofuels obtained from these materials. The RED II Directive, which entered into force on $7^{\text {th }}$ of January of 2021, reinforced the focus on raw materials (of lignocellulosic and non-lignocellulosic nature), residual or of low ILUC (energy crops on land of no or little agricultural aptitude) that, either by thermochemical or by biochemical conversion produces alcohols, dimethyl ether, hydrocarbons, hydrated vegetable oils (HVO), or other green biofuels as substitute for current fossil fuels.

Bioethanol (and other alcohols) - gasoline substitutes - The application of biochemical conversion technologies to lignocellulosic biomass results in the conversion of cellulose and hemicellulose into liquid biofuels (e.g., bioethanol, isobutanol, butanol). These technologies, which normally require several stages of biomass processing, through pre-treatment, enzymatic hydrolysis, and fermentation technologies, are already at precommercial TRL levels (TRL 7-8). Although there are still some technological barriers for their more extensive deployment. Among the most relevant are: i) energy intensity of the pre-treatment; ii) the intensification of the enzymatic process taking into account the limitations associated with the operation with high solids loads and enzyme load necessary to obtain saccharification yields above $85 \%$ that affects fermentation; iii) the final bioethanol yield necessary for economically viable processes that should reach a minimum value of $90 \%$ of the maximum theoretical yield and iv) the productivity required to make the bioconversion process economically viable that depends a lot on the type of sugars - C6 (hexoses) or C5 (pentoses) and their C5 / C6 - ratio to be used. Despite these operational difficulties, cellulosic bioethanol technology is clearly in a worldwide demonstration phase on an industrial scale and is expected to be cost-effective during this decade.

In addition to the production of ethanol as a biofuel substitute mainly for gasoline (it is also possible to completely replace diesel in road freight transport through ED95, a mixture with 95\% ethanol), there are other processes for converting biomass into higher alcohols (e.g. isobutanol, n-butanol), especially that these alcohols have higher calorific contents than ethanol. All these alcohols have the great advantage of being able to use the current fossil fuel distribution infrastructures (with minimal investment costs) and without any modification to the current generation of internal combustion engines for vehicles produced after the year 2000 . The main global players in the cellulosic bioethanol production technology are in Europe: Clariant, Germany; St1, Finland; Borregard, Norway; Futurol and CIMV, France; and Biochemtex/Versalis, Italy; in Brazil: Granbio, Alagoas and Raízen, São Paulo; and in India: Praj. All these industrial units, which started operating between 2012 and 2017, also carry out research and innovation actions aimed at optimising their technology, improving their performance and market position.

Biodiesel and HVO - diesel substitutes - The production of biodiesel is carried out on an industrial scale through a (trans)esterification reaction, in which the glycerides and/or free fatty acids present in each raw material are converted, in the presence of an alcohol and a catalyst, into esters. The most used commercial process to produce biodiesel, called FAME, from oil-based raw materials consists of a basic catalysis, sodium hydroxide or methylate, in the presence of methanol. In these processes, the biodiesel yield is around $85-90 \%$. The ILUC Directive [17]

https://doi.org/10.32933/Actalnnovations.39.4• ISSN 2300-5599 • C 2021 RIC Pro-Akademia - CC BY 
focused on replacing edible vegetable oils with residual raw materials such as used edible oils (OAU) and animal fats. The valorisation of bio-waste through the conversion of the oils/fats contained therein by transformation into an energy product (biodiesel) will be a sustainable alternative for their reduction/elimination. However, the RED II [1] intends to limit the use of these waste materials to $1.7 \%$, which means that there is a minimum margin of growth in the use of these waste materials. The reason behind this ceiling is the current distortion of the OAU market. For example, Portugal collects about 15000 tonnes of OAU annually from its HORECA channel but uses 190000 tonnes of OAU for biodiesel, i.e. almost 13-fold more. The difference lies in the import of OAU from 37 countries! Similar situations occur in almost all European countries.

Hydrotreated vegetable oil (HVO) is another biofuel substitute for diesel available on the market. HVO or green diesel has chemical properties identical to diesel, but it is obtained entirety from used vegetable oils or in coprocessing (mixed with oil) in a refinery environment. HVO, unlike diesel, does not emit NOx. In Europe, the main production players for this type of biofuel substitute for diesel are the Finnish oil company NESTE OIL (NexBTL technology [18]), with HVO producing units, ENI in Porto Marghera, which converted its oil refinery into a biorefinery dedicated to the production of HVO from virgin vegetable oils and used cooking oils, and the Finnish UPM, in Lappeenranta, with a mega factory producing green diesel from tall oil of the pulp industry operating since 2015.

Biokerosene (aviation) - The aviation fuel sector is a good example of the fact that the energy transition is not about electric mobility, but about liquid biofuels. Aviation needs effective options for carbon neutrality in the short to medium term, and the current biofuels on the road market (ethanol and biodiesel) do not meet the technical requirements to replace the jet aviation fossil jet-A1, due to the viscosity value at low temperatures as well as other non-compliant specifications in terms of energy density. ICAO predicts that in 2050 the aviation sector will contribute $2700 \mathrm{M}$ tonnes $\mathrm{CO}_{2}$ [19]. For this reason, the search for renewable alternatives is one of the main concerns of the aviation industry.

The main issue in the development of aviation biofuels is the reduction of the level of elemental oxygen present in the biomass with the aim of increasing the $\mathrm{H} / \mathrm{C}$ ratio (or the $\mathrm{H}_{\text {eff }} / \mathrm{C}$ ratio) in the biofuel. This can occur using hydroprocessing technology, already known to the petrochemical industry. All types and components of biomass can be used as raw material (polysaccharides, lignin, lipids), with greater or lesser efficiency, depending on how far the $\mathrm{H}_{\text {eff }} / \mathrm{C}$ ratio is from the values of interest, and this is always lower for sugars than for example, for lipids or other substrates such as bio-oils ( $\left.\mathrm{H}_{\mathrm{eff}} / \mathrm{C} \sim 1.8\right)$.

The main routes to produce aviation biofuels, already certified by ASTM, are the following:

- oleochemical processes such as the hydroprocessing of lipids (from oilseeds, algae, or animal fats), or the biomass pyrolysis to produce bio-oils and subsequent hydroprocessing and hydrocracking in biofuel aviation level. These processes are generally called HEFA technology.

- biochemical processes such as the conversion of lignocellulosic sugars to ethanol, long-chain alcohols, or hydrocarbons. These processes are generally called Alcohol to Jet (ATJ) technology.

- thermochemical/biochemical hybrid processes, e.g. biogas fermentation or aqueous phase reforming. These processes are generally called APR technology.

The transition to biofuels, in the aviation sector, should consider that three quarters of the world aviation are flights up to $1600 \mathrm{~km}$, so technological alternatives should focus on this segment, in a 1st phase. Current liquid biofuels can only be mixed directly with the fossil jet-A1 up to a percentage of the order of $50 \%$, as they do not meet all the requirements of the ASTM standards (e.g., \% aromatic hydrocarbon required). New drop-in biofuels that can directly replace the fossil jet $\mathrm{A} 1$ are found, for the time being at the level of laboratory development, and there is no certification for them.

Recycled fossil fuels - The use of fossil-based waste, e.g. non-recyclable plastics, used tires, etc., as well as the nonbiogenic $\mathrm{CO}_{2}$ emitted by industries of fossil origin, through thermochemical, catalytic, or biological processes produces new fuels, called low carbon fuels or recycled fuels. The main difficulty in assessing the sustainability potential of these fuels lies in the absence of any methodology provided for in RED II [1] that allows quantifying, in a comparative way, the savings in GHG emissions for these fuels. However, the European Commission by means of a delegated act, will propose a uniform methodology for calculating GHG emissions for these fuels, as well as will

https://doi.org/10.32933/Actalnnovations.39.4• ISSN 2300-5599 • C 2021 RIC Pro-Akademia - CC BY 
stipulate the minimum emission savings value that these fuels must achieve to be eligible for the minimum target of $14 \%$ renewables in transport in 2030. However, the final decision of whether to include them in this transport target or not is up to each Member State. In any case, these fuels cannot be the object of incentives through double counting.

\section{Impact}

The presented consideration shows that RED II will impact the electricity and heat sector through the introduction of sustainability criteria and thus, it will change the paradigm of the use of biomass in this sector by the minimum mandatory reductions of greenhouse gas (GHG) emissions and establishment of energy efficiency criteria.

The renewable fuels of non-biological origin are not eligible for double counting under RED II but are eligible for the multiplier factor of 1.2 on their energy content, if used in air and sea transport, as long as they reach a minimum reduction of GHG emissions of $70 \%$ for plants opened before $1^{\text {st }}$ of January 2021 . Hence, it can be considered that only maritime transport can benefit from this incentive from RED II, largely due to the recent restrictions on the use of fuels containing high levels of sulphur. For this, it is essential to invest in port infrastructures of compressed/liquefied natural gas, as only PtG or PtL technologies to have a margin of progression.

Regarding the hydrogen production, both renewable hydrogen production technologies will have similar development in terms of cost-efficiency in the medium term (2040), although in the longer term, the production of $\mathrm{H}_{2}$ by electrolysis may gain a decisive advantage due to three factors: reduction in the cost of electrolysers; cheaper $100 \%$ renewable electricity and possible increase in the price of natural gas. On the contrary, it can be emphasised that the growing use of water as a scarce good will only make this hydrogen production technology viable if it can be cost-efficient from non-potable water (sea, rivers, etc.).

In maritime transport, the need to liquefy gaseous biofuels (e.g. biomethane or $\mathrm{H}_{2}$ ) is a heavy economic burden for the consumer in the short-term. On the other hand, knowing that the current biodiesel is perfectly suitable to be mixed with the MFO, in a scenario of energy transition in the short-medium term with no or minimum investments in fuel distribution infrastructures in sea ports, the EU Member states should consider the allocation of incentives that promote the use of liquid or gaseous biofuels in maritime transport, without privileging any particular technology, but grading the incentives according to the maximization of the reduction of GHG emissions achieved by each biofuel. With the entry into force of RED II during the period 2021-2030, the bet on both electric mobility and advanced liquid biofuels for the road sector, will reduce the biodiesel-FAME market with serious economic consequences for the current companies that produce biodiesel from vegetable oils as a by-product of its activity of producing protein for animal feed. Hence, due to the penetration of electric mobility in urban transport, the aforementioned incentives would help to direct local or national supply of biodiesel-FAME to the maritime sector. On the other hand, the specifications of Marine Distillate Fuels according to ISO 8217-2017, indicate that the maximum percentage currently recommended for the addition of Biodiesel-FAME is 7\%, because the presence of biodiesel in higher quantities may increase the probability of microbial contamination, being pointed out as one of the problems of its use for maritime transport [20]. However, bet should be on port infrastructure of CNG/LNG, which can then be efficiently supplied by bio-CNG/bio-LNG (biomethane), or by PtG technologies. These technologies are considered as the only form of decarbonisation of maritime transport, as the electrification is not an alternative for this sector. However, in a market as competitive in terms of operating costs as the maritime one, the insertion of new bio-LNG/bio-GNC (biomethane) technologies or PtG technologies, seems only viable if it is a blend with the fuel currently used or blend with natural gas (e.g. diesel-natural gas hybrid ships).

The decarbonisation of long-distance road freight transport may have different scenarios according to the existing fuel distribution infrastructure or the one to be created. While in the short term, i.e. until 2030, cost-efficiency is clearly on the side of liquid biofuels, in the post-2030, both GNC (partially replaced by bio-GNC) and hydrogen (powered by electric fuel cell) seem to be the energy vectors that will emerge as the main ones as more severe emission restrictions are occurring in this transport sub-sector. However, the introduction of these new fuels (electricity, $\mathrm{H}_{2}$ ) will depend on the level of investment in the creation of basic supply infrastructures. Considering the horizon until 2030, biomethane is at a higher TRL, so due to its technological maturity, it will have a more relevant role in this energy transition. In addition, biomethane will assume a major role in the transport sector and is currently

https://doi.org/10.32933/Actalnnovations.39.4• ISSN 2300-5599 • (C) 2021 RIC Pro-Akademia - CC BY 
the best way to introduce the renewable component in transport. $\mathrm{H}_{2}$ will take over an increasing importance in the energy transition (much more than biomethane) but there are still economic challenges for its production and storage.

In short, a mix of all these energy vectors, including advanced liquid biofuels, must be invested in long-distance road freight transport, in the light of technological neutrality, so all solutions (short, medium and long term) must be considered and selected in view of their cost/benefit in reducing GHG emissions and their real contribution to achieving the goals of national and international commitments. To this end, it is essential to maximise the use of existing infrastructures, e.g. by total removal of natural gas and replacement with $100 \%$ hydrogen. This is because, in the case of mobility, the level of purity required in Fuel Cell electric vehicles prevents it from being obtained from natural gas- $\mathrm{H}_{2}$ mixtures, always requiring a dedicated European hydrogen supply infrastructure. In the case of bioGNC (biomethane), it can either be used locally in autonomous supply units (UAGs) or in filling stations along the European lines of the national gas transport network. The development of these alternative infrastructures should, however, evolve with the market, depending on technological progress, economic viability and consumer acceptance of the various forms of energy.

\section{Conclusions}

In conclusion, it can be stated that the evolution of electric mobility will only be effective for decarbonization when the addition of new capacity for electric energy from renewable sources and corresponding production, exceeds the increase in electricity consumption for mobility. Otherwise, this consumption will be made with electricity of fossil origin, with the corresponding associated emissions and without a positive contribution to the reduction of $\mathrm{CO}_{2}$ emissions. Additionally, it is recognised that the investment in the creation of production, storage and supply infrastructures takes time, which makes the importance of electric mobility for the effective decarbonisation of the transport sector becoming only significant in the post-2030/2035 period. On the other hand, even in the medium to long term, it is unlikely to have great penetration in long-distance road transport, due to weight/space limitations and autonomy, as well as its contribution to the sea and air. On the contrary, it will play a crucial role in in the light passenger road sector and even in the urban distribution goods sector that its penetration is most clearly anticipated until 2030. However, it cannot neglect that extensive development of charging points for the local, urban transport system will generate pressure and the need for investment in the national electricity network. This in turn will certainly have an impact on the value of the tariffs to be borne by the consumer. To mitigate this situation, in the medium term (post-2030) fuel cells may coexist and complement the batteries in electric mobility. This hypothesis will be viable, as long as $\mathrm{H}_{2}$ production and storage costs will be reduced. Considering that fuel cells in mobility can use both hydrogen and ethanol as a fuel source to produce electricity, the reduction of GHG emissions, environmental sustainability, social impact and the respective cost-effectiveness analysis should dictate the most appropriate solutions. With a view to using advanced biofuels in the energy transition period (2020-2050), it can be considered that it should also be a priority objective by 2030 to start a transition from the use of conventional biofuels to advanced biofuels, which allow substantial reductions in emissions of greenhouse gas and a well-to-wheel perspective allow to achieve total carbon neutrality. For that, it is necessary that there is a clear legislative framework that promotes the production of these biofuels and more importantly, that protects investors who intend to invest in biorefineries for advanced biofuels.

Finally, for these objectives to be achieved, it is necessary to adapt RED II to the national realities, so that no sector of the value chain (industry) or consumers is harmed. To this end, all stakeholders in the sector should have an essential role in the transposition of the RED II directive. The measures to promote the decarbonisation of the industry should respect the principle of technological neutrality by equally supporting all technologies and discriminating them against their contribution to the reduction of GHGs considering a complete life cycle analysis [21].

\section{Conflict of interest}

There are no conflicts to declare.

\section{Acknowledgments}

This research has not been supported by any external funding. 


\section{References}

[1] European Commission, Directive (EU) 2018/2001 of the European Parliament and of the Council of 11 December 2018 on the promotion of the use of energy from renewable sources, Off. J. Eur. Union. (2018). https://eur-lex.europa.eu/legal-content/EN/TXT/?uri=uriserv:OJ.L_.2018.328.01.0082.01.ENG.

[2] J. Ximenes, A. Siqueira, E. Kochańska, R.M. Łukasik, Valorisation of Agri- and Aquaculture Residues via Biogas Production for Enhanced Industrial Application, Energies. $14 \quad$ (2021) 2519. https://doi.org/10.3390/en14092519.[3] How are emissions of greenhouse gases by the EU evolving?, (2017). https://ec.europa.eu/eurostat/cache/infographs/energy/bloc-4a.html.

[4] Paris Agreement, The 21st Conference of the Parties (COP) of the United Nations Framework Convention on Climate Change, Paris, 2016.

[5] United Nations Climate Change Conference Marrakesh $2016 \quad$ - COP22, (2016). https://www.un.org/sustainabledevelopment/cop22/.

[6] Transport Decarbonisation Alliance, (2021). https://tda-mobility.org/.

[7] National Action Plans - Green Public Procurement, (2021). https://ec.europa.eu/environment/gpp/action_plan_en.htm.

[8] M. Materazzi, R. Taylor, The GoGreenGas case in the UK, in: Substit. Nat. Gas from Waste Tech. Assess. Ind. Appl. Biochem. Thermochem. Process., 2019: pp. 475-495. https://doi.org/10.1016/B978-0-12-8155547.00018-0.

[9] PDENH and ENGIE new partners in biomass energy plant Ambigo Alkmaar, (2017). https://www.ecn.nl/news/item/pdenh-and-engie-new-partners-in-biomass-energy-plant-ambigo-

alkmaar/.

[10] IMO 2020 Global Sulfur Cap, (2020). https://ww2.eagle.org/en/Products-and-Services/environmentalperformance/imo-2020-global-sulphur-cap.html.

[11] Suez canal blockage caused sulphur pollution spike, (2021). https://www.msn.com/en-xl/news/other/suezcanal-blockage-caused-sulphur-pollution-spike/ar-BB1fBLO6.

[12] The Debut of Costa Smeralda, Costa Cruises' New Ship Powered By LNG, (2020). https://www.carnivalcorp.com/news-releases/news-release-details/debut-costa-smeralda-costa-cruisesnew-ship-powered-Ing.

[13] Making Waves: First Ever Cruise Ship Sails on Battery Power, (2019). https://www.hurtigruten.com/abouthurtigruten/hurtigruten-news/first-ever-cruise-ship-sails-on-battery-power/.

[14] SHELL joins AIR LIQUIDE, NOURYON and ENERKEM as partner for Rotterdam Waste-to-Chemicals Project, (2019). https://www.chemengonline.com/shell-joins-air-liquide-nouryon-and-enerkem-as-partner-forrotterdam-waste-to-chemicals-project/.

[15] Enerkem to build EUR250 million facility in Spain, (2018). https://www.biofuelsdigest.com/bdigest/2018/05/09/enerkem-to-build-eur250-million-facility-in-spain/.

[16] VärmlandsMetanol AB, (2021). https://www.varmlandsmetanol.se/index.htm.

[17] European Commission, Directive 2015/1513 of the European Parliament and of the Council of 9 September 2015 amending Directive 98/70/EC relating to the quality of petrol and diesel fuels and amending Directive 2009/28/EC on the promotion of the use of energy from renewable sou, Off. J. Eur. Union. (2015). https://eur-lex.europa.eu/legal-content/EN/TXT/?uri=celex\%3A32015L1513.

[18] NEXBTL Technology, (2021). https://www.neste.com/about-neste/innovation/nexbtltechnology\#c5b76a37.

[19] P. Moran, Environmental Trends in Aviation to 2050, 2016. https://www.icao.int/Meetings/EnvironmentalWorkshops/Documents/Env-Seminars-Lima-

Mexico/Mexico/08_UnitedStates_EnvironmentTrends.pdf.

[20] ISO 8217:2017 Petroleum products - Fuels (class F) - Specifications of marine fuels, 2017. https://www.iso.org/standard/64247.html.

[21] M. Tabatabaei, M. Aghbashlo, The critical role of advanced sustainability assessment tools in enhancing the real-world application of biofuels, Acta Innov. $37 \quad$ (2020) 67-73. https://doi.org/10.32933/actainnovations.37.6. 